\title{
DESCRIPTION OF A NEW PROCERATIUM FROM MEXICO (HYMENOPTERA: FORMICIDAE)
}

\author{
By Roy R. SNELLING ${ }^{1}$ AND STEFAN P. COVER ${ }^{2}$
}

\section{INTRODUCTION}

Proceratium is a small genus of ectatommine Ponerinae containing fewer than three dozen known species, eight of which are found in the New World (Ward, 1988). That additional species remain to be discovered is evidenced by the new species described herein. We fully expect additional species to turn up in poorly collected forests of both the Old and New world tropics.

\section{TERMINOLOGY}

The following abbreviations are used for measurements and ratios.

CI - Cephalic index: (HW/HL) (100)

EL - Eye length: maximum eye length (diameter)

HL - Head length: with head in full frontal view, maximum measurable distance between upper margin of vertex and lower margin of clypeus.

HW - Head width: maximum measurable head width, in frontal view, excluding eyes.

IGR - Index of gastral reflection: length of gastral sternum 2/length of gastral tergum 2 (Ward, 1988)

SI - Scape index: (SL/HL) (100)

SL _ Scape length: length of scape shaft, exclusive of basal condyle.

TL - Total length: combined head length, Weber's length, petiole length, and gastral length.

WL - Weber's length: diagonal length of mesosoma from pronotal slope to distal edge of propodeal lamellae.

\footnotetext{
${ }^{1}$ Natural History Museum of Los Angeles County, 900 Exposition Boulevard, Los Angeles, Calif. 90007.

2 Museum of Comparative Zoology, Harvard University, Cambridge, Mass. 02138.

Manuscript received 12 July 1992
} 
Proceratium tio, new species

Figure 1

Diagnosis. - Similar to $P$. goliath Kempf and Brown but differs in being smaller, with more prominent propodeal teeth, and in possessing a distinctive spiniform subpetiolar process. In addition, $P$. tio has fewer than 10 erect hairs on the antennal scapes (vs. more than 20 for $P$. goliath), and the pilosity and pubescence on its scapes and upper body surfaces are shorter and much less dense than in P. goliath.

Description. - Holotype worker measurements (mm): HL (including clypeal lobe) 1.28; HW 1.18; SL 0.87: EL 0.08; WL 1.55; TL 5.26.

In frontal view, sides of head very weakly convex, almost straight, evenly rounded into moderately convex vertex; CI 92. Eye placed slightly below midlength of head, consisting of one clear, convex facet. Genal carina (="occipital carina" of Kempf and Brown, 1968) short but strong, ending at about level of eye and bounding an impressed, shiny gular area. Frontal line not evident above level of upper end of frontal lobes; frontal area deeply impressed; frontal carinae only slightly elevated, nearly flat. Apical margin of clypeal lobe narrowly transverse; disc without longitudinal costulae. Antennal scape thick, basal portion weakly curved, apex incrassate; when laid back along front of head, apex well below vertex margin; SI 68. Mandible with 4-toothed, oblique margin; outer face coarsely costulate.

Mesosoma compact, convex above, sutures obsolete. Propodeal teeth short and blunt; declivity concave in both directions, distinctly carinate on each side, disc transversely rugulose above; inferior propodeal lamellae low and rounded. Propodeal spiracle small, nearly round.

Petiole low, loaf-shaped, sessile, about 0.8 times as high as long and about 0.9 times as broad as long, broadest at about posterior third. Subpetiolar process conspicuous, spiniform, at about midlength of segment.

Gaster broad and strongly recurved, IGR 0.13 , second tergum strongly rounded, but less strongly extended distad than in $P$. goliath. In dorsal view postpetiole (first tergum) distinctly broader 


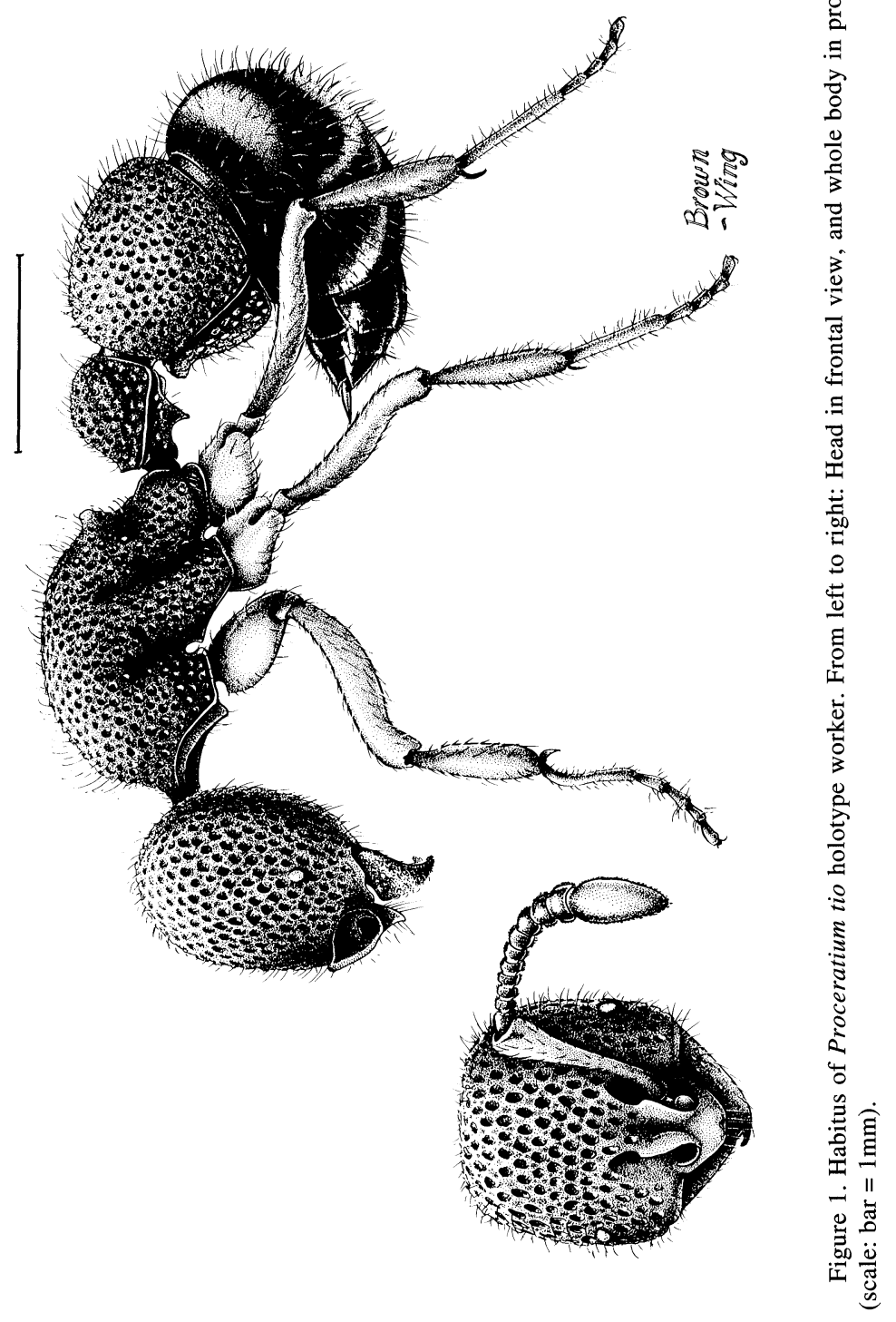


than long; second tergum slightly shorter and slightly wider than first.

Legs long (metafemur $1.14 \mathrm{~mm}$ long and metatibia $0.87 \mathrm{~mm}$ long) and slender, greatest thickness of metafemur about 0.18 times length. Tibial spur pectinate, tarsal claws slender and simple.

Head, mesosoma, petiole, and postpetiole densely and coarsely rugosopunctate, punctures piligerous, deep and crowded, their bottoms weakly to moderately shiny; second and following gastral segments shiny, with numerous, though scattered, minute piligerous punctures.

Vestiture brassy to golden in color, consisting of abundant fine prostrate to suberect pubescence and numerous much longer and coarser suberect to erect hairs.

Color generally brownish-red, antennae and legs more yellowish.

Type material. - Described from unique holotype worker: MEXICO, Veracruz: $6 \mathrm{mi}$ NE Catemaco, $1500 \mathrm{ft}$. elev., 7 July 1976 (A. Newton), from rainforest leaf litter berlesate; deposited in Museum of Comparative Zoology.

Etymology. - Respecting "Uncle" Bill Brown's disdain for patronymics, we have, with affectionate perversity, chosen to dedicate this species to him by choosing the Spanish word for "uncle."

Discussion. - In the most recent key to New World Proceratium species, that of Ward (1988), P. tio will fail at couplet 4: although a pectinate mesotibial spur is present, the median lobe of the clypeus is truncate at the apex, rather than emarginate. The clypeal character aside, this ant will key to $P$. goliath, from which it differs as noted in the diagnosis above.

We should note that we disagree with the original characterization of scape length provided by Kempf and Brown (1968). In their description of $P$. goliath the apex of the scape is said to just surpass the posterior margin of the head (i.e., the vertex) when "held as nearly straight back" as possible. Our study of the holotype and one paratype found that the apex of the scape falls well short of the margin of the vertex; the SI of the type is 72 , that of the paratype is 73. Figures 1 and 2 by Kempf and Brown show the correct scape length and the SI in the figure is also 73 . 


\section{ACKNOWLEDGMENTS}

To Kathy Brown-Wing we are very deeply indebted for the very fine habitus figure of $P$. tio.

\section{LiteratuRE Cited}

KempF, W. W., AND W. L. Brown, JR.

1968. Report on some neotropical ant studies. Papeis Avuls. Zool. 22: 89-102.

WARD, P. S.

1988. Mesic elements in the western nearctic ant fauna: taxonomic and biological notes on Amblyopone, Proceratium, and Smithistruma (Hymenoptera: Formicidae). Pan-Pacif. Ent. 61: 102-124. 

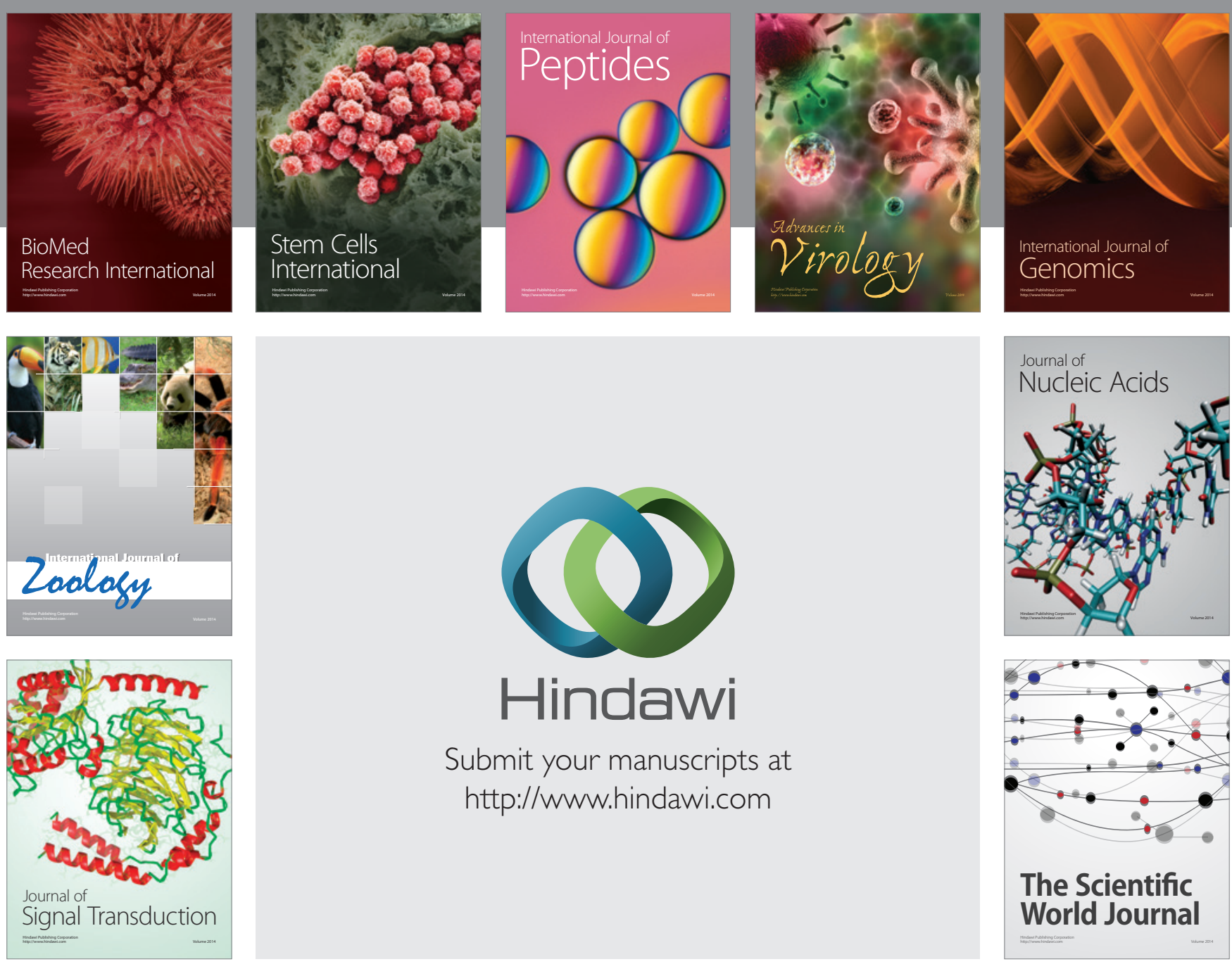

Submit your manuscripts at

http://www.hindawi.com
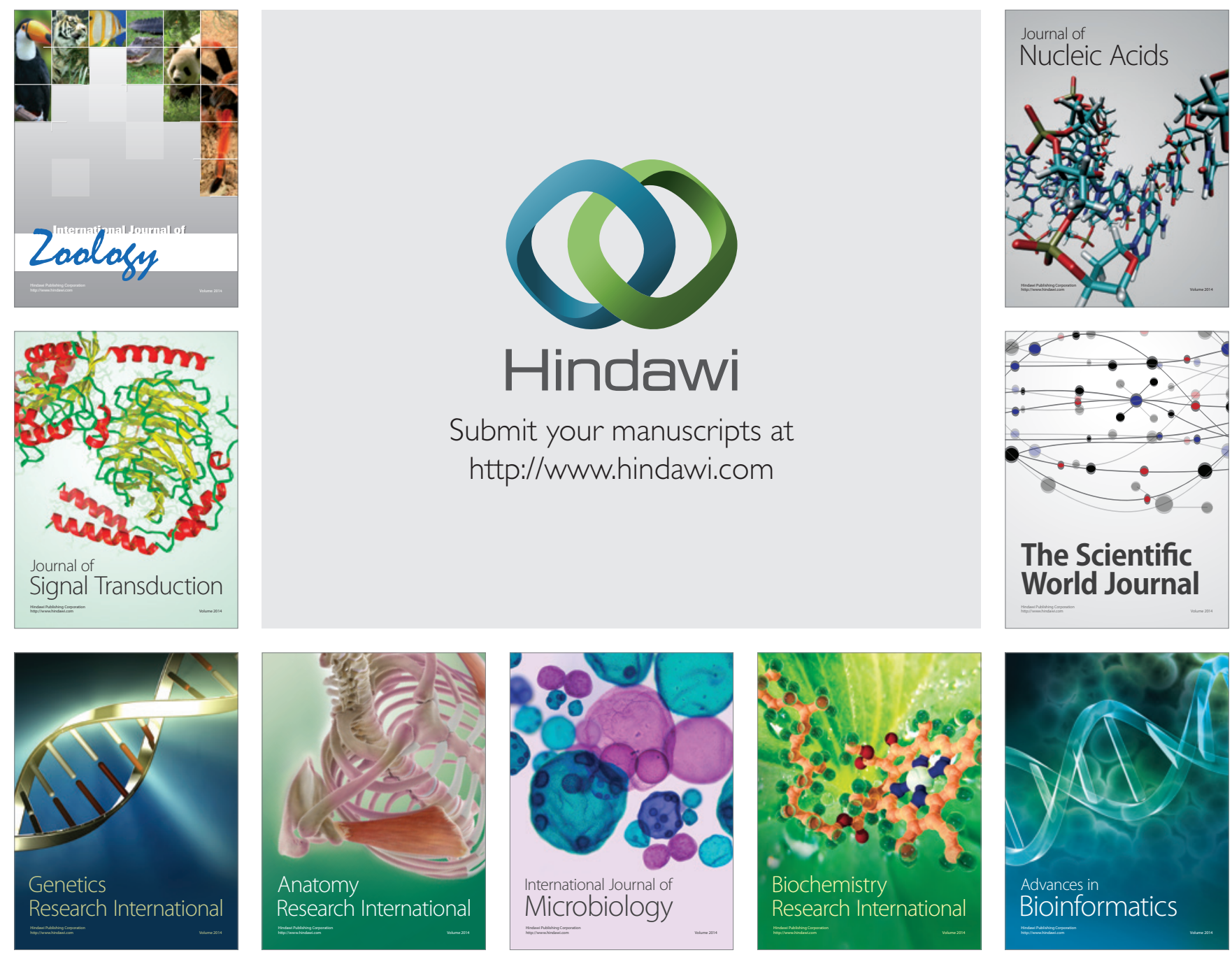

The Scientific World Journal
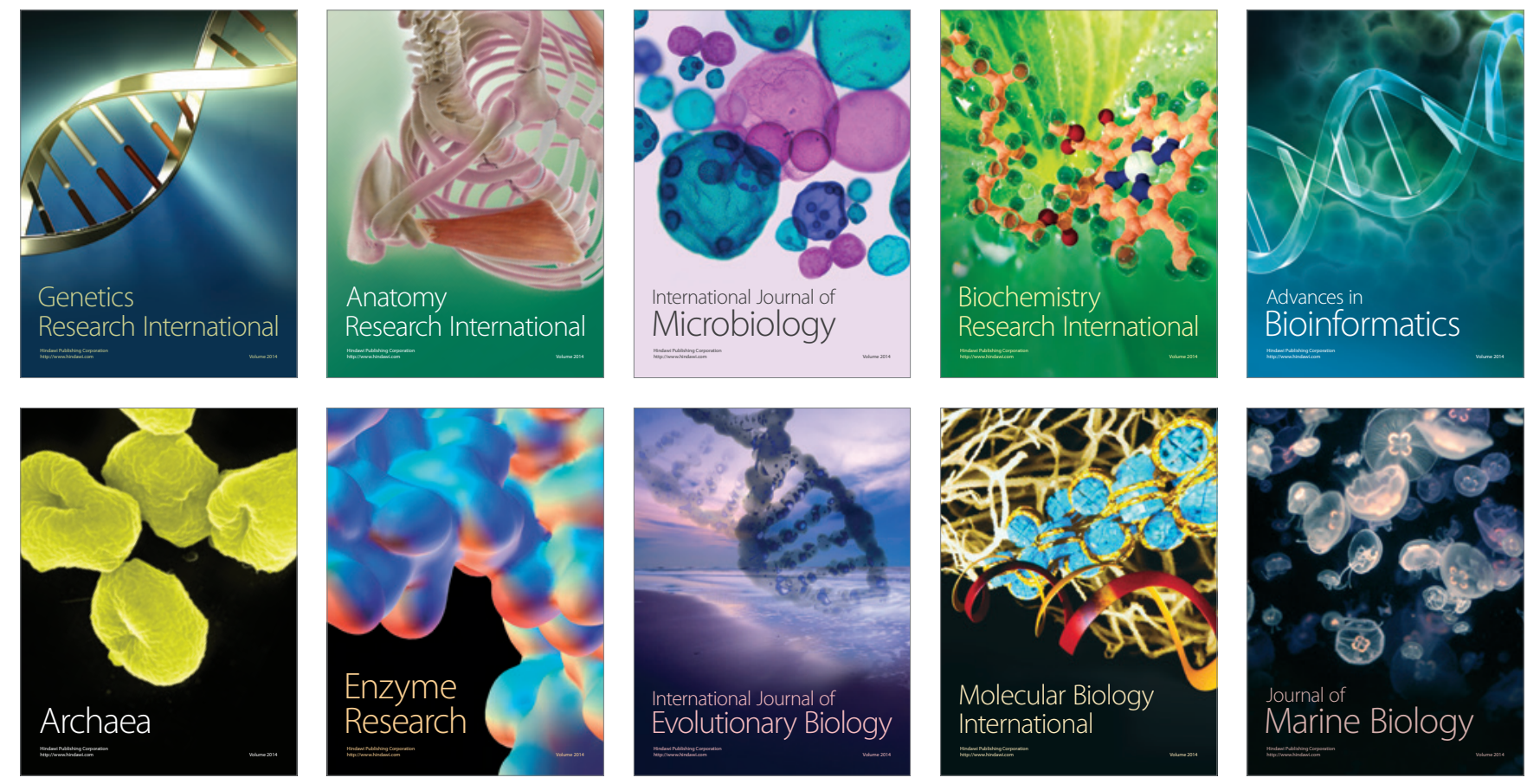